\title{
Orthodontic Treatment Effect on Inclination of Maxillary Incisors and Growth Axes in Adult Patients with Various Mandibular Divergent Patterns
}

\author{
Samar Bou Assi ${ }^{1}$, Ziad Salameh ${ }^{2}$, Antoine Hanna $^{3}$, Josephine Aybout ${ }^{4}$, Anthony Macari ${ }^{5}$
}

\begin{abstract}
Aim: To evaluate, in an adult population, the effect of orthodontic treatment on the inclination of maxillary incisors, facial, and growth axes in different mandibular divergence pattern. In addition, we aimed to determine if there is an association between the inclination of the maxillary incisors and facial and growth axes and if this association will change after orthodontic treatment.

Materials and methods: Two-hundred and thirty-eight consecutive lateral cephalograms (119 at T1 and 119 at T2) of adult patients with an average age of $26.45 \pm 9.11$ years at $\mathrm{T} 1$ and $29.58 \pm 9.36$ at T2 were selected and digitized. Cephalometric maxillary incisors (I) inclination was measured to cranial base (SN), palatal plane (PP), nasion-A point (NA), nasion-basion (NBa), and true horizontal (H). Facial (FA) and growth (GA) axes' inclinations were measured relative to $\mathrm{NBa}$ and $\mathrm{H}$. The sample was stratified in three subgroups based on cephalometric mandibular divergence to anterior SN (MP/SN). A-Hypodivergent $=\mathrm{MP} / \mathrm{SN} \leq 27^{\circ}(n=28)$; B-Normodivergent $=27<\mathrm{MP} / \mathrm{SN}<37^{\circ}(n=49) ; \mathrm{C}-$ Hyperdivergent $=\mathrm{MP} /$ $\mathrm{SN} \geq 37^{\circ}(n=42)$. Associations were tested using Chi-square tests for categorical data. Paired sample $t$-tests and Pearson's correlation were computed for continuous data.

Results: At T1, there was a tendency to have more proclined I in group A $\left(\mathrm{I} / \mathrm{SN}=105.59 \pm 10.8^{\circ}\right)$ and more retroclined in group $\mathrm{C}$ $\left(\mathrm{I} / \mathrm{SN}=99.06 \pm 12.04^{\circ}\right)$ with no statistical significance. However, at $\mathrm{T} 2$, maxillary incisors were statistically significant different between groups A and C $(p=0.002)$. Pre-treatment FA and GA were statistically significantly different among the three divergence groups $(p<0.0001)$ with more increased angles in the group $A\left(F A / N b a=92.77 \pm 5.07^{\circ}\right)$ vs group $C\left(F A / N b a=86.28 \pm 5.08^{\circ}\right)$. This angle increases around $2^{\circ}$ on average at posttreatment assessment (group $\mathrm{A}-p=0.033$; group $\mathrm{B}-p=0.002$ ). Correlations between I and facial/growth axes were not statistically significant at T1, whereas at T2 those correlations were higher and statistically significant between I/PP to FA/NBa ( $r=0.408 ; p \leq 0.0001)$.

Conclusion: Correlations between the maxillary incisors' inclination and the facial/growth axes were not statistically significant initially whereas after orthodontic treatment, those correlations were higher and statistically significant. Differences in FA existed between pre- and postorthodontic groups in all divergence groups.

Clinical significance: Orthodontists should assess the inclination of the maxillary incisors, not only to the maxilla and anterior SN but also to FA and take it into consideration in their treatment objectives.

Keywords: Facial axis, Growth axis, Incisors, Mandibular divergence, Posttreatment.

The Journal of Contemporary Dental Practice (2021): 10.5005/jp-journals-10024-3191
\end{abstract}

\section{INTRODUCTION}

The maxillary incisors' inclination (I) is a major component of smile and facial esthetics. ${ }^{1,2}$ Therefore, it must be assessed during treatment planning, when judging treatment progress and in assessing treatment outcome. ${ }^{3}$ Achieving an optimal I of the maxillary incisors after orthodontic treatment should be an objective to ensure facial harmony and constitutes a primary goal to attain. ${ }^{1}$

To improve the prediction of the optimal I of the maxillary incisors, many cephalometric and profilometric measurements have been suggested. ${ }^{4-8}$ While the cephalometric I of the maxillary incisors has been extensively studied, its potential association with the facial pattern, namely the facial axis (FA) and growth axis (GA), has not been thoroughly investigated.

The facial axis (FA), as initially described by Ricketts, is the angle between NBa plane and the line extending from foramen rotundum (Pt) to constructed gnathion (Fig. 1). It has a mean of $90 \pm 3.5^{\circ}$ and is indicative of the facial type. Therefore, it indicates the direction of growth and varies among vertical and horizontal patterns..$^{4,9}$ In hypodivergent patients, the FA is increased, and the face grows down and forward, as opposed to hyperdivergent patients who
${ }^{1,3-5}$ Division of Orthodontics and Dentofacial Orthopedics, American University of Beirut, Beirut, Lebanon

${ }^{2}$ Director of Research Centers, Faculty of Dental Medicine, Lebanese University, Beirut, Lebanon

Corresponding Author: Samar Bou Assi, Division of Orthodontics and Dentofacial Orthopedics, American University of Beirut, Beirut, Lebanon, Phone: +961-3-461944, e-mail: sbouassi@ul.edu.lb

How to cite this article: Bou Assi S, Salameh Z, Hanna A, et al. Orthodontic Treatment Effect on Inclination of Maxillary Incisors and Growth Axes in Adult Patients with Various Mandibular Divergent Patterns. J Contemp Dent Pract 2021;22(9):1008-1013.

Source of support: Nil

Conflict of interest: None

Associations were evaluated using Chi-square tests for categorical data. Paired sample $t$-tests and Pearson's correlation were computed for continuous data. For all parameters, two-sided $p$-values were reported. $p<0.05$ was considered as statistically significant. All analyses were completed using IBM SPSS Statistics 
show a decreased FA measurement and a downward and backward direction of growth.

Similarly, the GA, as described by Downs, is the angle between sella turcica (S) to gnathion (Gn) line and Frankfort horizontal line (Fig. 1). It ranges from 53 to $66^{\circ}$, with a mean reading of $59.4 \pm 3.8^{\circ}$. This angle indicates the growth pattern of the mandible. ${ }^{4,10}$

In the literature, there is a lack of categorical assessment of the I of the maxillary incisors after orthodontic treatment; although there are numerous reports on different facial patterns and malocclusions, not all malocclusions were considered. Chrivella et al. found the I of the maxillary incisors to differ among different facial types. ${ }^{11}$ Mollabashi et al. concluded that this I was similar in class (CLII) div 1 cases treated with different mechanics. ${ }^{12}$ Burns et al. showed significant changes in this I in CLIII patients treated with camouflage orthodontic tooth movement. ${ }^{13}$ Troy et al. found no difference in maxillary incisors' I between CLIII surgical and camouflage groups after treatment, ${ }^{14}$ while Zou et al. found significant changes in this I in CLIII cases after surgery; ${ }^{15}$ thus, our aim was to assess pre- and posttreatment maxillary incisors' I relative to FA and GA as both axes are reflective of the vertical and sagittal discrepancies and the facial type of the patient. To the best of our knowledge, this is the first attempt to assess such a potential association at pre- and postorthodontic treatments.

Accordingly, the main objective of this study was to compare the changes in pre- vs posttreatment I of the maxillary incisors and I of FA and GA after orthodontic treatment in different mandibular divergence patterns. The secondary aim was to determine the potential association between the I of the maxillary incisors and FA and GA in an adult orthodontic population, if this association will change after orthodontic treatment.

\section{Materials and Methods}

This is a retrospective cohort study. The study duration was 1 year. The material was comprised of 119 pre- and 119 posttreatment lateral cephalograms of Caucasian adult subjects ( 85 females and 34 males) selected from patients' data at the department (name of the institution). Their mean age was $26.45 \pm 9.11$ (Table 1). Prior to the conduct of the study, signed consent to use the radiographs was obtained from the patients. The inclusion criteria were Caucasian

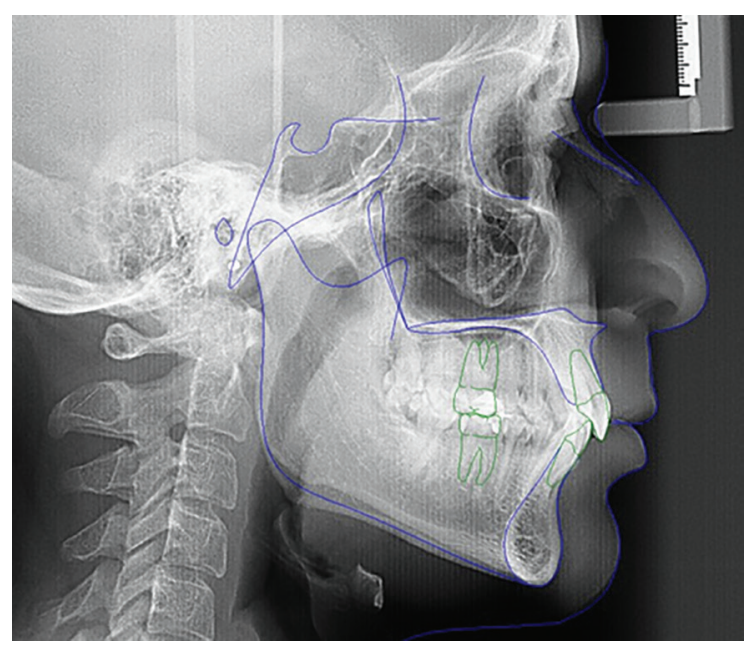

Fig. 1: Digitized lateral cephalogram patients, nongrowing (chronological age above 16 years for girls and 18 years for boys), with available lateral cephalometric radiographs taken prior to and at the end of orthodontic treatment (after the removal of appliances). The following conditions were the basis for exclusion: previous orthodontic and/or orthognathic surgery treatment; the presence of any craniofacial anomaly; and this retrospective study was approved by the Institutional Review Board at the American University of Beirut, Beirut, Lebanon (OTO. AM.01). The study duration was 6 months.

Sample size calculation was performed before initiating data collection. With an anticipated effect size of 0.5 , a power level of 0.8 , a probability level of 0.05 , and with the number of observed and unobserved variables used in the structural equation model of this study, a minimum sample size of 89 subjects was required.

Available lateral cephalometric radiographs taken prior to and at the end of orthodontic treatment placed according to the natural head position at an appropriate distance (sagittal plane-film distance of $13 \mathrm{~cm}$ ), all with the same machine, were studied.

A total of 238 lateral cephalograms (119 at T1 and 119 at T2) were digitized using the Dolphin orthodontic software (Dolphin Imaging and Management Solutions, La Jolla, California, United States) (Fig. 1). Different variables were measured on the digitized lateral cephalograms, and angular measurements were computed to determine the I of maxillary incisors to cranial base (SN), palatal plane (PP), nasion-A point (NA), NBa, and true horizontal (H), and facial and growth axes' Is were measured relative to NBa and $\mathrm{H}$ (Fig. 2).

The sample was then stratified into three groups depending on the divergence based on MP/SN angle: $A$-hypodivergent $=\mathrm{MP}$ / $\mathrm{SN} \leq 27^{\circ}(n=28) ; \mathrm{B}$-normodivergent $=27<\mathrm{MP} / \mathrm{SN}<37^{\circ}(n=49)$; and $\mathrm{C}$-hyperdivergent $=\mathrm{MP} / \mathrm{SN} \geq 37^{\circ}(n=42)$. To determine the intra-observer reliability, a single investigator repeated all angular and linear cephalometric measurements on 30 randomly selected cephalographs (nearly $20 \%$ of the sample).

\section{Statistical Analyses}

After conducting data cleaning for any potential errors, an initial frequency distribution was generated for all variables to check for any potential outliers. The intraclass correlation coefficient was computed for all quantitative measures to assess inter-rater reliability.

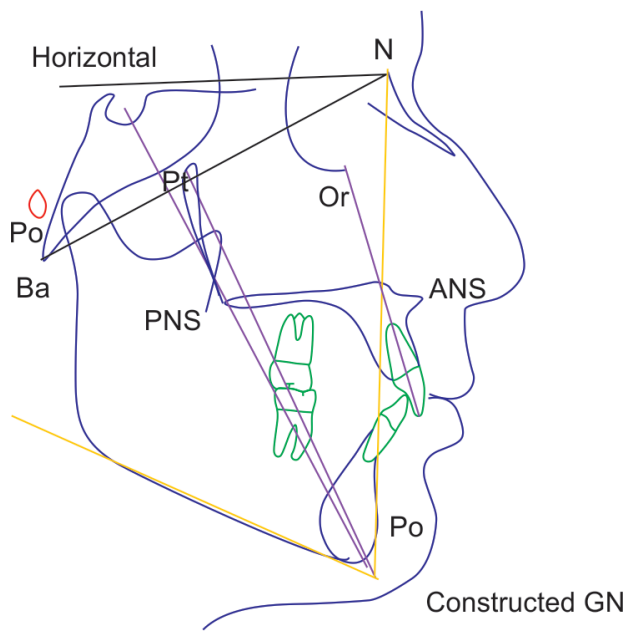

Fig. 2: Lateral cephalometric tracing with landmarks and planes used in the study including facial and growth axes and maxillary incisor's long axis 
Orthodontic Treatment Effect on Maxillary Incisors' Inclination and Growth Axes

Table 1: Means of age and selected cephalometric measurements in groups $\mathrm{T} 1$ and $\mathrm{T} 2$ for the whole sample and groups $\mathrm{A} / \mathrm{B}$ and $\mathrm{C}$

\begin{tabular}{|c|c|c|c|c|c|c|c|c|c|c|c|c|c|}
\hline & & \multicolumn{2}{|c|}{$\begin{array}{l}H Y P O \\
N=28\end{array}$} & \multicolumn{2}{|c|}{$\begin{array}{c}\text { NORMO } \\
N=49\end{array}$} & \multicolumn{2}{|c|}{$\begin{array}{l}\text { HYPER } \\
N=42\end{array}$} & \multicolumn{2}{|c|}{$\begin{array}{c}\text { Total } \\
N=119\end{array}$} & \multirow[b]{2}{*}{ ANOVA } & \multirow[b]{2}{*}{$A-B$} & \multirow[b]{2}{*}{$A-C$} & \multirow[b]{2}{*}{$B-C$} \\
\hline \multicolumn{2}{|c|}{ Variable } & Mean & $S D$ & Mean & $S D$ & Mean & $S D$ & Mean & $S D$ & & & & \\
\hline \multirow[t]{4}{*}{ Age } & $\mathrm{T} 1$ & 26.93 & 8.44 & 25.75 & 8.89 & 26.94 & 9.91 & 26.45 & 9.11 & 0.79 & NS & NS & NS \\
\hline & $\mathrm{T} 2$ & 29.38 & 8.40 & 29.09 & 9.23 & 30.29 & 10.24 & 29.58 & 9.36 & 0.83 & NS & NS & NS \\
\hline & $p$ & $<0.0001$ & & $<0.0001$ & & $<0.0001$ & & $<0.0001$ & & & & & \\
\hline & $\mathrm{T} 2-\mathrm{T} 1$ & 2.44 & 2.82 & 3.24 & 2.13 & 3.35 & 1.46 & 3.09 & 2.13 & 0.18 & 0.35 & 0.24 & NS \\
\hline \multirow[t]{4}{*}{ I/NA } & $\mathrm{T} 1$ & 23.6 & 9.3 & 19.35 & 10.46 & 20.51 & 10.01 & 20.76 & 10.1 & 0.20 & 0.23 & 0.63 & NS \\
\hline & $\mathrm{T} 2$ & 22.76 & 6.68 & 20.22 & 7.82 & 19.18 & 8.98 & 20.45 & 8.06 & 0.19 & 0.55 & 0.21 & NS \\
\hline & $p$ & 0.633 & & 0.502 & & 0.236 & & 0.694 & & & & & \\
\hline & $\mathrm{T} 2-\mathrm{T} 1$ & -0.84 & 9.18 & 0.88 & 9.08 & -1.33 & 7.18 & -0.31 & 8.47 & 0.43 & NS & NS & 0.653 \\
\hline \multirow[t]{4}{*}{ I/PP } & $\mathrm{T} 1$ & 109.15 & 22.28 & 109.39 & 10.21 & 108.7 & 10.35 & 109.09 & 13.9 & 0.97 & NS & NS & NS \\
\hline & $\mathrm{T} 2$ & 112.94 & 7.89 & 110.29 & 5.91 & 107.64 & 9.09 & 109.98 & 7.82 & 0.02 & 0.44 & 0.02 & 0.31 \\
\hline & $p$ & 0.351 & & $<0.0001$ & & 0.399 & & 0.450 & & & & & \\
\hline & $\mathrm{T} 2-\mathrm{T} 1$ & 3.79 & 21.14 & 0.9 & 9.33 & -1.06 & 8.08 & 0.89 & 12.79 & 0.30 & NS & 0.37 & NS \\
\hline \multirow[t]{4}{*}{ I/SN } & $\mathrm{T} 1$ & 105.59 & 10.8 & 101.59 & 10.68 & 99.06 & 12.04 & 101.64 & 11.38 & 0.06 & 0.40 & 0.06 & 0.86 \\
\hline & $\mathrm{T} 2$ & 106.26 & 7.54 & 103.36 & 6.17 & 99.62 & 9.23 & 102.72 & 8.04 & 0.002 & 0.34 & 0.002 & 0.07 \\
\hline & $p$ & 0.698 & & $<0.0001$ & & 0.707 & & 0.204 & & & & & \\
\hline & $\mathrm{T} 2-\mathrm{T} 1$ & 0.66 & 8.95 & 1.77 & 9.31 & 0.56 & 9.55 & 1.08 & 9.25 & 0.8 & NS & NS & NS \\
\hline \multirow[t]{4}{*}{ ANB } & $\mathrm{T} 1$ & 3.41 & 2.39 & 3.03 & 3.3 & 4.44 & 2.87 & 3.62 & 2.3 & 0.075 & NS & 0.48 & 0.08 \\
\hline & $\mathrm{T} 2$ & 3.33 & 2.37 & 3.44 & 2.8 & 5.13 & 3.76 & 4.01 & 3.17 & 0.016 & NS & 0.06 & 0.03 \\
\hline & $p$ & 0.682 & & 0.078 & & 0.263 & & 0.105 & & & & & \\
\hline & $\mathrm{T} 2-\mathrm{T} 1$ & -0.09 & 1.1 & 0.40 & 1.57 & 0.69 & 3.95 & 0.39 & 2.61 & 0.48 & NS & 0.67 & NS \\
\hline \multirow{4}{*}{$\begin{array}{l}\mathrm{FA} / \\
\mathrm{Nba}\end{array}$} & $\mathrm{T} 1$ & 92.77 & 5.07 & 89.96 & 4.03 & 86.28 & 5.084 & 89.32 & 5.27 & $<0.0001$ & 0.04 & $<0.0001$ & 0.001 \\
\hline & $\mathrm{T} 2$ & 93.42 & 4.66 & 91.35 & 3.4 & 85.93 & 3.72 & 89.93 & 4.89 & $<0.0001$ & 0.07 & $<0.0001$ & $<0.0001$ \\
\hline & $p$ & 0.033 & & 0.002 & & 0.624 & & 0.061 & & & & & \\
\hline & $\mathrm{T} 2-\mathrm{T} 1$ & 0.65 & 1.53 & 1.39 & 2.98 & -0.35 & 4.59 & 0.6 & 3.47 & 0.06 & NS & 0.7 & 0.05 \\
\hline \multirow{4}{*}{$\begin{array}{l}\text { FA/ } \\
\text { Horiz }\end{array}$} & $\mathrm{T} 1$ & 119.07 & 7.49 & 118.34 & 3.24 & 115.47 & 4.24 & 117.5 & 5.07 & 0.004 & NS & 0.009 & 0.02 \\
\hline & $\mathrm{T} 2$ & 121.84 & 8.161 & 123.1 & 7.94 & 110.28 & 10.33 & 118.28 & 10.65 & $<0.0001$ & NS & $<0.0001$ & $<0.0001$ \\
\hline & $p$ & 0.099 & & $<0.0001$ & & 0.002 & & 0.377 & & & & & \\
\hline & $\mathrm{T} 2-\mathrm{T} 1$ & 2.78 & 8.59 & 4.76 & 6.91 & -5.19 & 10.04 & 0.78 & 9.57 & $<0.0001$ & 0.98 & 0.001 & $<0.0001$ \\
\hline \multirow{4}{*}{$\begin{array}{l}\mathrm{GA} / \\
\mathrm{Nba}\end{array}$} & $\mathrm{T} 1$ & 92.01 & 11.4 & 94.13 & 3.89 & 90.93 & 5.54 & 92.50 & 6.97 & 0.08 & 0.59 & NS & 0.09 \\
\hline & $\mathrm{T} 2$ & 90.07 & 10.19 & 93.58 & 3.14 & 89.44 & 3.85 & 91.29 & 6.06 & 0.002 & 0.04 & NS & 0.003 \\
\hline & $p$ & 0.059 & & 0.218 & & 0.068 & & 0.004 & & & & & \\
\hline & $\mathrm{T} 2-\mathrm{T} 1$ & -1.94 & 5.21 & -0.55 & 3.11 & -1.5 & 5.17 & -1.21 & 4.45 & 0.37 & 0.57 & NS & 0.95 \\
\hline GA/ & $\mathrm{T} 1$ & 128.41 & 13.26 & 120.98 & 14.5 & 120.6 & 3.88 & 122.6 & 11.9 & 0.01 & 0.02 & 0.02 & NS \\
\hline Horiz & $\mathrm{T} 2$ & 128.32 & 13.33 & 123.67 & 5.18 & 120.66 & 3.79 & 123.7 & 8.06 & $<0.0001$ & 0.03 & $<0.0001$ & 0.19 \\
\hline & $p$ & 0.805 & & 0.207 & & 0.930 & & 0.223 & & & & & \\
\hline & $\mathrm{T} 2-\mathrm{T} 1$ & -0.1 & 2.04 & 2.69 & 14.73 & 0.06 & 4.18 & 1.11 & 9.85 & 0.34 & 0.70 & NS & 0.62 \\
\hline I/Nba & $\mathrm{T} 1$ & 107.86 & 26.59 & 83.33 & 12.6 & 82.35 & 10.18 & 88.76 & 19.39 & $<0.0001$ & $<0.0001$ & $<0.0001$ & NS \\
\hline & $\mathrm{T} 2$ & 109.51 & 24.02 & 84.77 & 9.17 & 81.23 & 9.01 & 89.34 & 17.97 & $<0.0001$ & $<0.0001$ & $<0.0001$ & 0.7 \\
\hline & $p$ & 0.169 & & 0.277 & & 0.391 & & 0.444 & & & & & \\
\hline & $\mathrm{T} 2-\mathrm{T} 1$ & 1.64 & 6.16 & 1.43 & 9.13 & -1.12 & 8.35 & 0.58 & 8.27 & 0.25 & NS & 0.52 & 0.43 \\
\hline 1/Horiz & $\mathrm{T} 1$ & 112.38 & 9.56 & 108.62 & 17.57 & 111.74 & 10.12 & 110.61 & 13.6 & 0.41 & 0.74 & NS & 0.84 \\
\hline & $\mathrm{T} 2$ & 114.02 & 7.29 & 108.33 & 15.43 & 106.63 & 9.24 & 109.07 & 12.12 & 0.04 & 0.14 & 0.04 & NS \\
\hline & $p$ & 0.158 & & 0.821 & & $<0.0001$ & & 0.051 & & & & & \\
\hline & $\mathrm{T} 2-\mathrm{T} 1$ & 1.64 & 5.97 & -0.29 & 9.05 & -5.11 & 8.19 & -1.54 & 8.5 & 0.002 & 0.95 & 0.003 & 0.017 \\
\hline MP/SN & $\mathrm{T} 1$ & 23.09 & 2.65 & 32.16 & 2.84 & 44.63 & 16.15 & 34.43 & 12.85 & $<0.0001$ & 0.001 & $<0.0001$ & 0.001 \\
\hline & $\mathrm{T} 2$ & 23.69 & 3.52 & 30.93 & 3.51 & 40.59 & 4.74 & 32.64 & 7.64 & $<0.0001$ & $<0.0001$ & $<0.0001$ & $<0.0001$ \\
\hline & $p$ & 0.198 & & 0.008 & & 0.116 & & 0.054 & & & & & \\
\hline & $\mathrm{T} 2-\mathrm{T} 1$ & 0.6 & 2.40 & -1.23 & 3.1 & -4.04 & 16.3 & -1.79 & 10.04 & 0.15 & N.S & 0.18 & 0.55 \\
\hline
\end{tabular}


Orthodontic Treatment Effect on Maxillary Incisors' Inclination and Growth Axes

\begin{tabular}{llllllllllllll}
\hline IMPA & T1 & 97.35 & 7.75 & 93 & 8.85 & 90.96 & 6.93 & 93.3 & 8.26 & 0.005 & 0.07 & 0.004 & 0.68 \\
& T2 & 96.55 & 11.14 & 95.97 & 8.67 & 93.39 & 6.79 & 95.2 & 8.77 & 0.24 & NS & 0.42 & 0.49 \\
& $p$ & 0.568 & & 0.004 & & 0.010 & & 0.003 & & & & \\
& T2-T1 & -0.8 & 7.28 & 2.98 & 6.91 & 2.44 & 5.87 & 1.9 & 6.77 & 0.05 & 0.06 & 0.15 & NS \\
I/I & T1 & 131.83 & 14.96 & 134.62 & 14.24 & 128.58 & 11.81 & 131.83 & 13.75 & 0.11 & NS & 0.99 & 0.11 \\
& T2 & 130.96 & 13.82 & 129.6 & 9.67 & 126.37 & 10.24 & 128.78 & 11.03 & 0.19 & NS & 0.27 & 0.49 \\
& $p$ & 0.722 & & 0.014 & & 0.134 & & 0.007 & & & & & \\
& T2-T1 & -0.87 & 12.83 & -5.03 & 13.71 & -2.21 & 9.39 & -3.06 & 12.16 & 0.31 & 0.45 & NS & 0.82 \\
\hline
\end{tabular}

version 27 (IBM, released 2020, IBM SPSS Statistics for Windows, version 27.0, Armonk, New York).

\section{Results}

The intraclass correlation coefficient for intra-examiner reliability was high (>0.9). The sample included 85 female and 34 male subjects. When classified on gender, no statistically significant differences were present at initial or posttreatment time points for all measured variables. Thus, statistical analyses were applied on to the whole sample as one entity irrespective of the gender. At $\mathrm{T} 1$, the average age for the whole sample was $26.45 \pm 9.11$ years, and at $\mathrm{T} 2,29.58 \pm 9.36$ years. Upon stratification into divergence groups, group A of hypodivergent pattern included 28 subjects with a mean age of $26.93 \pm 8.44$ years at $\mathrm{T} 1$ and $29.38 \pm 8.4$ years at T2 (Table 1). Group B of normodivergent pattern had 49 individuals with a mean age of $25.75 \pm 8.89$ years at $\mathrm{T} 1$ and $29.09 \pm 9.23$ years at T2. Group C of hyperdivergent pattern included 42 patients with a mean age of $26.94 \pm 9.91$ years at $\mathrm{T} 1$ and $30.29 \pm 10.24$ years at $\mathrm{T} 2$. Whether at $\mathrm{T} 1$ or at $\mathrm{T} 2$, age was not statistically significantly different between groups $A, B$, and $C$.

\section{Comparisons of Cephalometric Measurements of the Total Sample between $\mathrm{T} 1$ and $\mathrm{T} 2$}

When the total sample of 119 patients was analyzed, most of the studied parameters were not statistically significantly different between T1 and T2 except for GA/NBa $(p=0.004)$ and mandibular incisors/MP ( $p=0.003)$. MP/SN decreased by around $2^{\circ}\left(\mathrm{T} 1=34.43^{\circ}\right.$; $\left.\mathrm{T} 2=32.64^{\circ}\right)$ but was not statistically significantly different.

\section{Comparisons of Cephalometric Measurements between Groups A, B, and C at T1}

At T1, maxillary incisors' I was not statistically significantly different between the three divergence groups (Table 1), but with a tendency to have more proclined maxillary incisors in group $A$ of hypodivergent $\left(\mathrm{I} / \mathrm{SN}=105.59 \pm 10.8^{\circ}\right)$ and more retroclined in group $C$ of hyperdivergent $\left(\mathrm{I} / \mathrm{SN}=99.06 \pm 12.04^{\circ}\right)$. In addition, ANB angle was not statistically different. However, FA and GA were statistically significantly different among the three divergence groups $(p<0.0001)$ with more increased angles in group $\mathrm{A}$ (FA/ $\left.\mathrm{NBa}=92.77 \pm 5.07^{\circ}\right)$ vs group $\mathrm{C}\left(\mathrm{FA} / \mathrm{NBa}=86.28 \pm 5.08^{\circ}\right)$, i.e., hypodivergent vs hyperdivergent (Table 1). In addition, mandibular incisors to MP were more proclined in group A $\left(97.35 \pm 7.75^{\circ}\right)$ than group $C\left(90.96 \pm 6.93^{\circ}\right)$ with $p=0.004$ (Table 1).

\section{Comparisons of Cephalometric Measurements between Groups A, B, and C at T2}

At $T 2$, maxillary incisors were statistically significantly different mainly between groups $A$ and $C(p=0.002)$. Significant differences also existed between groups $A, B$, and $C$ for ANB angle and growth and facial axes' Is to NBa and $\mathrm{H}$. However, mandibular incisors were not statistically significantly different with IMPA $=96.55 \pm 11.14^{\circ}$ for group A and $93.39 \pm 6.79^{\circ}$ for group C (Table 1).

\section{Comparisons of Cephalometric Measurements at T1 vs T2}

The FA/NBa was statistically significantly different in group A (hypodivergent) at T1 vs T2 $(p=0.033)$ and in group B (normodivergent) $(p=0.002)$ with a tendency to increase by around $2^{\circ}$ on average. In addition, $\mathrm{FA} / \mathrm{H}$ was also significantly different in groups $B$ and $C$ between $T 1$ and $T 2$ with corresponding $p$-values of $<0.0001$ and 0.002 , respectively. Maxillary incisors did not show any statistically significant differences in the hypo-and hyperdivergent groups, but only in the normodivergent group with an increase in I/SN by $1.77^{\circ}$ at $p<0.0001$ (Table 1). Mandibular incisors increased significantly in groups $\mathrm{B}\left(+2.98^{\circ} ; p=0.004\right)$ and $\mathrm{C}\left(+2.44^{\circ} ; p=0.01\right)$ but decreased in group $\mathrm{A}\left(-0.8^{\circ}\right)$.

\section{Correlations}

At T1, correlations between maxillary incisors' I and FA and GA were not statistically significant. $R$ values were low for I/PP, $\mathrm{I} / \mathrm{SN}, \mathrm{I} / \mathrm{NBa}$, and $\mathrm{I} / \mathrm{H}$ ranging from 0.004 to 0.389 (Table 2). Similarly, correlations between MP/SN and incisors' I were not statistically significant ( $p=0.978$ ) except for I/NBa: $R=-0.282$ with $p=0.002$.

On the opposite and at T2, higher and statistically significant positive correlations existed between maxillary incisors' I and FA and GA (Table 2). At T2, I/PP correlated significantly with FA/NBa $(r=0.408 ; p \leq 0.0001)$ and with FA/H $(r=0.286 ; p=0.002)$. Similarly, $\mathrm{I} / \mathrm{SN}$ and I/NBa correlated significantly with FA/NBa $(r=0.491$; $p \leq 0.0001$ and $r=0.456 ; p \leq 0.0001$ correspondingly) and with $\mathrm{FA} / \mathrm{H}(r=0.330 ; p \leq 0.001$ and $r=0.183 ; p=0.047$ correspondingly) (Table 2).

In addition, strong and statistically significant negative correlations existed between MP/SN angle and FA and GA at preand posttreatment assessment with $r$ values ranging from -0.360 to -0.709 at $p<0.0001$. The negative correlation increased between $\mathrm{T} 1$ and $\mathrm{T} 2$.

While ANB angle negatively correlated with FA and GA at $\mathrm{T} 1$, these correlations became stronger at statistically significant differences. At T1, ANB angle correlated with FA/NBa at $r=-0.319$; $p \leq 0.001$, which increased to $r=-0.428 ; p \leq 0.0001$ (Table 2).

\section{Discussion}

In this study, we evaluated the effect of orthodontic treatment on the I of the maxillary incisors, the FA and GA in different mandibular vertical patterns. The classification of the three divergence groups was based on the angulation of the mandibular plane (MP) to the 


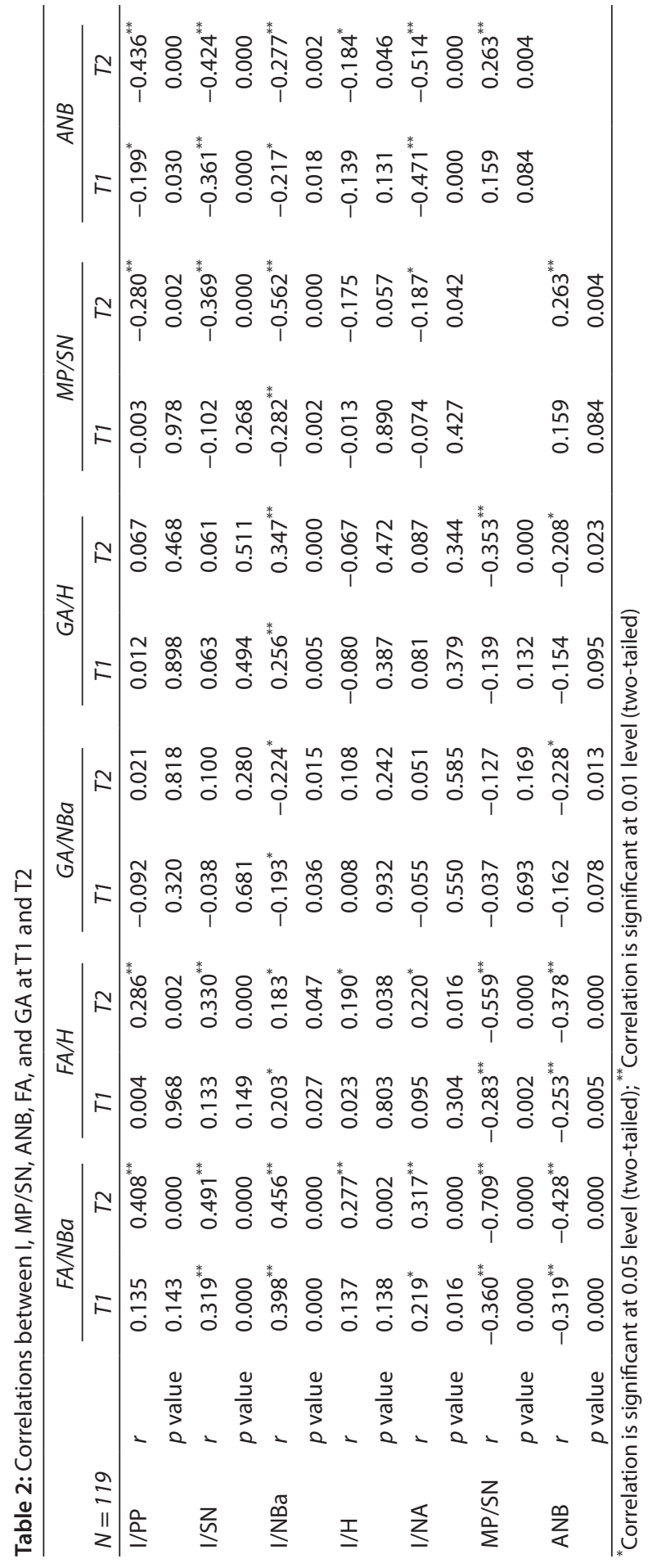

anterior SN. In addition, we aimed to assess the potential correlation between the I of the maxillary incisors and FA and GA in an adult orthodontic population and if this association changes after orthodontic treatment.

The main outcomes were that at $\mathrm{T} 1$, maxillary incisors' I was not statistically significantly different between the three divergence groups but with a tendency to have more proclined maxillary incisors in the hypodivergent group and more retroclined in the hyperdivergent group; similarly, the mandibular incisors were more proclined in the hypo- than in the hyperdivergent group.

Amjad et al. ${ }^{16}$ found in their study on $\mathrm{T} 1$ lateral cephalograms that maxillary and mandibular incisors' I was greater in hyperdivergent patients as compared to hypodivergent patients. Their results differ from the findings of the present study as their sample included only CLI patients, whereas our sample included all malocclusions.

In our findings, correlations between the maxillary incisors' I and the FA and GA were not statistically significant in $T 1$, whereas in T2, those correlations were higher and statistically significant. When comparing $\mathrm{T} 1$ to $\mathrm{T} 2$ measurements, FA/NBa was statistically significantly different in the hypo- and normodivergent groups and $\mathrm{FA} / \mathrm{H}$ was also significantly different in the normo- and hyperdivergent groups. Maxillary incisors showed statistically significant differences only in the normodivergent group and mandibular incisors increased significantly in the normo- and hyperdivergent groups but decreased in the hypodivergent group.

FA and GA describe the position of the mandible in the vertical and sagittal planes. ${ }^{9,10}$ In growing patients, they indicate the path of growth describing a normal, vertical, or horizontal growth vector of the mandible. ${ }^{9,10}$ However, in nongrowing patients, the FA and GA remain stable and therefore can be used as a reliable cephalometric reference to measure maxillary incisors' I. ${ }^{9,10}$ On the contrary, maxillary incisors' optimal I plays a major role in profile and smile esthetics and is an essential goal to attain in orthodontic treatment and it has not been associated before with the I of FA and GA. ${ }^{1,2}$

In a previous study, the authors determined that while FA/NBa was different when classified in vertical and sagittal groups, differences in maxillary incisors' I existed only among the different sagittal groups but not among the different vertical groups. ${ }^{17}$ Accordingly, in this study, pre- and postorthodontic treatment comparison evaluates the potential changes induced by orthodontic treatment to the association between maxillary incisors' I and FA and GA.

Our sample included adult patients treated only orthodontically with no surgical treatment to exclude any major mandibular repositioning and subsequent changes in FA and GA. In this perspective, changes in FA and GA were considered minor and statistically not significant. However, the correlations of those axes to the maxillary incisors' I increased significantly after treatment. To the best of our knowledge, this was the first time that such an association was evaluated on adult subjects. These significant correlations are essentially the reflection of the optimization of maxillary incisors' I through orthodontic treatment in each individual. Consequently, the cephalometric evaluation of maxillary incisors' I to FA and GA may be an additional valid method to diagnosis and may be sought as a treatment objective.

\section{Research Issues and Limitations}

Our sample was consisted of adult patients. It would be interesting to longitudinally follow the growing patients to evaluate the 
maxillary incisors' I changes relative to FA and GA. Most clinicians rely on radiographs to evaluate the I of the maxillary incisors; however, study dental casts have been used by some considering that radiographic digitization is difficult and prone to errors. ${ }^{18,19}$ In our study, we used lateral cephalometric radiographs to assess the maxillary incisors' I, and dental casts were discarded as they are considered not valid, especially with inappropriate trimming.

\section{Conclusion}

Maxillary incisors exhibited different I's in the pretreatment evaluation in correspondence with the divergence patterns. However, these differences were more accentuated after the treatment with more proclination in the hypodivergent group. Similarly, the mandibular incisors were more proclined in the hypodivergent than the hyperdivergent group. The orthodontic treatment induced minor changes in the FA and GA. Nevertheless, significant higher correlations between the Is of the maxillary incisors and the FA existed at the posttreatment time point.

Thus, orthodontists need to highlight the relationship between the maxillary incisors and FA and GA prior to treatment as it may be important in setting the final incisors' I outcome.

\section{References}

1. Doshi P, Kalia A, Patil W, et al. Evaluation of the effect of maxillary incisor labiolingual inclination and anteroposterior position on smiling profile esthetics: A computer aided photographic study. Sci J Res Dentistry 2017;1(2):043-049.

2. Cao L, Zhang K, Bai D, et al. Effect of maxillary incisor labiolingual inclination and anteroposterior position on smiling profile esthetics. Angle Orthod 2011; 81(1):121-129. DOI: 10.2319/033110-181.1.

3. Richmond S, Klufas ML, Sywanyk M. Assessing incisor inclination: a non-invasive technique. Eur J Orthod 1998;20(6):721-726. DOI: 10.1093/ejo/20.6.721.

4. Jacobson A, Jacobson R. Radiographic cephalometry from basics to 3-D imaging. 2nd ed. Chicago, London: Quintessence Pub.; 2006.

5. Ellis E 3rd, McNamara JA Jr. Cephalometric evaluation of incisor position. Angle Orthod 1986;56(4):324-344. DOI: 10.1043/0003-32 19(1986)056<0324:CEOIP>2.0.CO;2.

6. Naini FB. Facial aesthetics: concepts and clinical diagnosis. London: Wiley-Blackwell; 2011.
7. Singh G. Textbook of Orthodontics. 2nd ed. New Delhi: Jaypee; 2007 p. 517.

8. Arnett W, McLaughlin R. Facial and dental planning for orthodontists and oral surgeons. London: Mosby; 2004.

9. Ricketts RM. Cephalometric analysis and synthesis. Angle Orthod 1961;31(3):141-156. Available from https://doi.org/10.1043/00033219(1961)031<0141:CAAS>2.0.CO;2

10. William B Downs. Analysis of the dentofacial profile. Angle Orthod 1956;26(4):191-212. DOI: 10.1043/0003-3219(1956)026 $<0191:$ AOTDP>2.0.CO;2.

11. Chirivella P, Singaraju GS, Mandava P, et al. Comparison of the effect of labiolingual inclination and anteroposterior position of maxillary incisors on esthetic profile in three different facial patterns. J Orthod Sci 2017;6(1):1-10. DOI: 10.4103/2278-0203.197387.

12. Mollabashi V, Kazemisaleh A, Seyedtabib M. Final maxillary incisor inclination in Class II Div 1 malocclusion treated with standard edge wises or straight wire appliances. J Clin Diagn Res 2019;13(9):44-49. DOI: 10.7860/JCDR/2019/41541.13173.

13. Burns N, Musich D, Razmuz T, et al. Class III camouflage treatment: what are the limits? Am J Orthod Dentofacial Orthop 2010;137(1):9-13. DOI: 10.1016/j.ajodo.2009.05.017.

14. Troy B, Shanker S, Fields H, et al. Comparison of incisor inclination in patients with Class III malocclusion treated with orthognathic surgery or orthodontic camouflage. Am J Orthod Dentofacial Orthop 2009;135(2):146-147. DOI: 10.1016/j.ajodo.2008.07.012.

15. Zou B, Zhou Y, Lowe A, et al. Changes in anteroposterior position and inclination of the maxillary incisors after surgical-orthodontic treatment of skeletal Class III malocclusions. J Craniomaxillofac Surg 2015;43(10):1986-1993. DOI: 10.1016/j.jcms.2014.12.013.

16. Amjad N, Mahmood A, Masood RT, et al. Comparison of incisors inclination in hyperdivergent and hypodivergent patients. Pakistan O Dent J 2019;39(2):125-128.

17. Bou Assi S, Macari A, Hanna A, et al. Cephalometric evaluation of maxillary incisors inclination, facial, and growth axes in different vertical and sagittal patterns: an original study. J Int Soc Prevent Communit Dent 2020;10(3):292-299. DOI: 10.4103/jispcd.JISPCD_60_20.

18. Nouri M, Abdi AH, Farzan A, et al. Measurement of the buccolingual inclination of teeth: Manual technique vs 3-dimensional software. Am J Orthod Dentofacial Orthop 2014;146(4):522-529. DOI: 10.1016/j. ajodo.2014.06.018.

19. Houston WB. The analysis of errors in orthodontic measurements. Am J Orthod 1983;83(5):382-390. DOI: 10.1016/0002-9416(83)90322-6. 